\title{
Vochysiaceae no Parque Nacional da Serra da Canastra, Minas Gerais, Brasil
}

\author{
Vochysiaceae from Serra da Canastra National Park, Minas Gerais, Brazil
}

\author{
Deise Josely Pereira Gonçalves ${ }^{1,2,4}$, Rosana Romero ${ }^{1} \&$ Kikyo Yamamoto $^{3}$
}

\begin{abstract}
Resumo
No Parque Nacional da Serra da Canastra, localizado a sudoeste do estado de Minas Gerais, foram encontradas 11 espécies de quatro gêneros da família Vochysiaceae: Vochysia, com cinco espécies ( $V$. cinnamomea Pohl, V. elliptica Mart., V. sessilifolia Warm., V. thyrsoidea Pohl e V. tucanorum Mart.), Qualea com quatro espécies (Q. cordata Spreng., Q. grandiflora Mart., Q. multiflora Mart. e Q. parviflora Mart.) e Callisthene e Salvertia com uma espécie cada, C. major Mart. e S. convallariodora A.St.-Hil. O presente artigo fornece chave de identificação e descrições das espécies, dados de distribuição geográfica, comentários taxonômicos e ilustrações dos caracteres diagnósticos.

Palavras-chave: cerrado, campo rupestre, florística.
\end{abstract}

\begin{abstract}
In Serra da Canastra National Park, located in southwestern Minas Gerais state, we found 11 species belonging to four Vochysiaceae genera: Vochysia with five species (V. cinnamomea Pohl, V. elliptica Mart., $V$. sessilifolia Warm., V. thyrsoidea Pohl and V. tucanorum Mart.), Qualea with four species (Q. cordata Spreng., Q. grandiflora Mart., Q. multiflora Mart. and Q. parviflora Mart.), and Callisthene and Salvertia with one species each, C. major Mart. and S. convallariodora A.St.-Hil. This article provides a species identification key, species descriptions with geographic data, taxonomic remarks and illustration of diagnostic characters.

Key words: cerrado, campo rupestre, floristics.
\end{abstract}

\section{Introdução}

Vochysiaceae A.St.-Hil. compreende mais de 200 espécies (Litt \& Stevenson 2003) distribuídas principalmente nas florestas tropicais e savanas, especialmente do Brasil, onde está representada por 160 espécies (França 2013). A família é tradicionalmente dividida entre as tribos Vochysieae Dumort. e Erismeae Dumort. (Dumortier 1829), que se diferenciam por características do ovário e do fruto (Litt \& Stevenson 2003). Vochysiaceae compreende plantas lenhosas de folhas simples com estípulas (glandulares em Qualea Aubl. e Ruizterania Marc.-Berti) e geralmente opostas ou verticiladas; possui flores zigomorfas arranjadas em inflorescências terminais ou axilares (Callisthene); o cálice é 5-mero, gamossépalo e calcarado (exceto em Qualea subgênero Amphilochia (Mart.) Stafleu); a corola (0-) 1, 3 ou 5-mera e pode ser decídua na antese; o androceu composto por um único estame fértil também pode ser decíduo na antese (no gênero Vochysia); o ovário é súpero (Vochysieae) ou ínfero (Erismeae), 3-carpelar, 1 ou 3-locular, com 1 a vários óvulos por lóculo em placentação axilar ou apical, 1 estilete e 1 estigma. A família é importante na caracterização de fitofisionomias do domínio dos Cerrados, sendo considerada um componente típico destas formações vegetais (Sarmiento 1983).

A localização da Serra da Canastra entre as elevações ao sul da Serra do Espinhaço e as serras de Goiás é um importante aspecto fitogeográfico da área (Romero \& Martins 2002). Após alguns anos realizando coletas sistemáticas no Parque Nacional da Serra da Canastra (PNSC), Romero \& Nakajima (1999) confirmaram a importância florística desta

\footnotetext{
${ }^{1}$ Universidade Federal de Uberlândia, Inst. Biologia, C.P. 593, 38400-902, Uberlândia, MG, Brasil.

${ }^{2}$ Universidade Estadual de Campinas, Inst. Biologia, Depto. Biologia Vegetal, Programa de Pós-Graduação em Biologia Vegetal, C.P. 6109, 13083-862, Campinas, SP, Brasil.

${ }^{3}$ Universidade Estadual de Campinas, Inst. Biologia, Depto. Biologia Vegetal, C.P. 6109, 13083-862, Campinas, SP, Brasil.

${ }^{4}$ Autor para correspondência: deisejpg@utexas.edu, deisejpg@gmai.com
} 
Unidade de Conservação onde registraram um total de 768 espécies de angiospermas, sendo 45 espécies endêmicas e 37 espécies novas. Após as listagens de espécies das famílias Asteraceae (Nakajima \& Semir 2001) e Melastomataceae (Romero \& Martins 2002), os trabalhos sobre o PNSC compreendem os tratamentos sistemáticos sobre Annonaceae (Pontes \& Mello-Silva 2005), Apocynaceae-Asclepiadoideae (Farinaccio \& Mello-Silva 2004), Apocynaceae s. str. (Morokawa et al. 2013), Bignoniaceae (Scudeller 2004), Chrysobalanaceae (Hemsing \& Romero 2010), Leguminosae-Papilionoideae (Filardi et al. 2007), Malpighiaceae (Volpi 2006), Melastomataceae das serras de Delfinópolis (Silva \& Romero 2008), Piperaceae (Carvalho-Silva \& Guimarães 2009) e Rubiaceae-Rubioideae (Silveira 2010).

O presente trabalho dá continuidade ao estudo da flora do Complexo da Serra da Canastra e tem como objetivo apresentar descrições, chave de identificação, dados de distribuição geográfica e comentários taxonômicos das espécies de Vochysiaceae, além de ilustrações das características diagnósticas.

\section{Material e Métodos}

O Parque Nacional da Serra da Canastra (PNSC) localiza-se na porção sudoeste do estado de Minas Gerais e foi criado em 3 de abril de 1972 por meio do decreto federal $n^{\circ}$ 70.355 , com uma área de aproximadamente 200.000 ha. Nesta área estão compreendidos dois grandes blocos, o Chapadão da Canastra e o Chapadão da Babilônia. O primeiro trata-se de uma área contínua e regularizada, com área total de 71.525 ha distribuídos nos municípios de São Roque de Minas, Delfinópolis e Sacramento. O segundo bloco, com aproximadamente 130.000 ha, trata-se de uma área que ainda não foi regularizada e que abrange os municípios de Delfinópolis, São João Batista do Glória, Capitólio e Vargem Bonita (Ibama 2005). O presente estudo foi realizado utilizando amostras coletadas no Chapadão da Canastra e no Chapadão da Babilônia.

A vegetação do PNSC e de seu entorno está inserida no domínio fitogeográfico do Cerrado e engloba fitofisionomias savânicas (cerrado sentido restrito, cerrado rupestre), campestres (campo limpo, campo sujo, campo rupestre) e florestais (floresta mesófila, matas ciliares, mata de encosta e cerradão) (Ibama 2005).
As descrições da família e das espécies foram baseadas em todos os materiais provenientes do PNSC encontrados nos herbários HUFU, UEC e SPFR. Há duplicatas da coleção do HUFU nos herbários K, MBM, RB, SPFR e UEC (siglas segundo Thiers 2012). Para evitar a redundância de materiais semelhantes e de localidades próximas, são listados apenas dois materiais examinados por espécie, um com flor e um com fruto pré-deiscente, sempre que possível. Na ausência de espécimes em fruto foram utilizados, nas descrições, materiais provenientes de outras áreas e estes são citados como "Material adicional examinado".

A identificação dos espécimes foi realizada com base nos trabalhos de Stafleu (1948; 1952; 1953) e Yamamoto (2009). A terminologia morfológica segue Radford et al. (1974). Os termos incurvo (curvado para dentro, em direção ao pedicelo) e recurvo (curvado para fora, em direção oposta ao pedicelo), referentes à curvatura do cálcar, seguem Stearn (2004) e os dados foram tomados de flores após a antese. Descrições originais e fotografias dos tipos também foram analisadas, quando possível. Dados de floração e frutificação foram retirados das etiquetas dos espécimes coletados no PNSC. A distribuição geográfica geral das espécies é baseada em dados encontrados em Tropicos (Tropicos 2013) e Lista de Espécies da Flora do Brasil (Lista de Espécies da Flora do Brasil 2013).

\section{Resultados e Discussão}

A família Vochysiaceae está representada no Parque Nacional da Serra da Canastra por 11 espécies, sendo Vochysia o gênero mais representativo, com cinco espécies, seguido de Qualea com quatro espécies, e Callisthene e Salvertia A. St.-Hil. com uma espécie cada. Três espécies de Vochysia pertencem à subseção Decorticantes (Warm.) Stafleu da seção Vochysiella Stafleu e duas à subseção Lutescentes (Warm.) Stafleu da seção Ciliantha Stafleu. O gênero Qualea é representado por três espécies do subgênero Qualea, seção Costatifolium Stafleu e uma espécie do subgênero Amphilochia. Já Callisthene é representado no PNSC por apenas uma espécie pertencente à seção Callisthene, enquanto Salvertia não possui classificação infragenérica por se tratar de um gênero monotípico (Stafleu 1948).

De acordo com a lista de espécies ocorrentes no Cerrado, apresentada por Mendonça et al. (2008), Vochysiaceae apresenta 44 espécies, das 
quais ca. $25 \%$ ocorrem no PNSC. Um levantamento florístico realizado no município de Pedregulho, São Paulo, relaciona sete espécies de Vochysiaceae (Sasaki \& Mello-Silva 2008), das quais seis também ocorrem no PNSC. Estes autores atribuem à proximidade geográfica e à similaridade geológica a composição florística semelhante do extremo nordeste do estado de São Paulo e dos Planaltos da Serra da Canastra. A fitofisionomia predominante no PNSC é o campo rupestre, onde ocorrem nove dos 11 táxons encontrados. Dez táxons ocorrem em campo rupestre ou cerrado. Dentre estes últimos, constam as espécies Qualea multiflora Mart. e Vochysia tucanorum que ocorrem principalmente em florestas de galeria e ocasionalmente em campo rupestre e cerrado rupestre. Callisthene major Mart. ocorre estritamente em florestas.
Tratamento taxonômico Vochysiaceae A.St.-Hil.

Árvores, arbustos ou subarbustos. Folhas simples, inteiras, opostas ou verticiladas, estípulas decíduas ou persistentes, neste caso geralmente glandulares, venação reticulada, glabras ou com indumento variado em densidade, de esparso a denso. Tirso terminal e/ou axilar ou flores isoladas (apenas em Callisthene); flores vistosas, monóclinas, diclamídeas, zigomorfas; corola com uma pétala em Callisthene e Qualea, três pétalas em Vochysia e cinco pétalas em Salvertia; cálice gamossépalo apenas na base, calcarado (exceto em Qualea subgênero Amphilochia); monandras, antera biteca, deiscência longitudinal; ovário súpero, tricarpelar, trilocular; estilete e estigma simples. Fruto capsular loculicida; sementes aladas.

\section{Chave para identificação das espécies de Vochysiaceae do Parque Nacional da Serra da Canastra}

1. Folhas opostas dísticas, dispostas em râmulos semelhantes a uma folha pinada

1. Callisthene major

1'. Folhas opostas cruzadas ou verticiladas, não dispostas em râmulos semelhantes a uma folha pinada ....... 2

2. Estípulas glandulares ou glândulas na região das estípulas; flores com 1 pétala; no fruto aberto, valvas não fundidas à região central e margens não reflexas .

2'. Ausência de estípulas glandulares ou de glândulas na região das estípulas; flores com 3 ou 5 pétalas; no fruto aberto, valvas parcialmente fundidas à região central e margens reflexas

3. Cálice desprovido de cálcar, apenas com protuberância bursiforme na base da quarta sépala

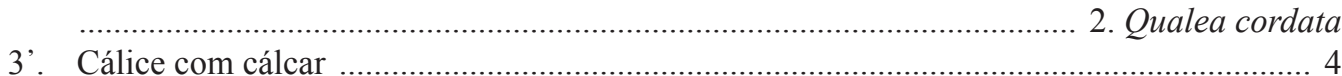

4. Casca dos ramos descamante; cálcar dobrado entre as sépalas, não aparente no botão floral; pétala 3,5-4 × 4-4,5 cm

4'. Casca dos ramos íntegra; cálcar aparente no botão floral; pétala 1,5-2 × 1,2-2,5 cm ..

5. Pétala alva ou amarela com manchas róseas a vináceas; cápsula com superfície verruculosa, não descamante

5'. Pétala violácea a vinácea com manchas lilases; cápsula com superfície lisa, levemente descamante

6. Lâmina foliar $14-23 \times 6-14 \mathrm{~cm}$; corola com 5 pétalas

6. Salvertia convallariodora

6'. Lâmina foliar 7-19 × 1,5-6 cm; corola com 3 pétalas .............................. 7

7. Ramos reprodutivos com casca descamante em placas; ovário seríceo..

7'. Ramos reprodutivos com casca íntegra, não descamante em placas; ovário glabro

8. Folhas indumentadas, congestas no ápice dos ramos

7. Vochysia cinnamomea

8'. Folhas glabras, não congestas, dispostas ao longo dos ramos ..... 9

9. Botão floral com ápice agudo ou apiculado

8. Vochysia elliptica

9'. Botão floral com ápice arredondado .... 9. Vochysia sessilifolia 
10. Lâmina foliar coriácea, margem fortemente revoluta em toda a lâmina; frutos $3-4 \mathrm{~cm}$ compr.

10. Vochysia thyrsoidea

10'. Lâmina foliar cartácea, margem plana, às vezes levemente revoluta apenas na porção basal; frutos ca. $1,8 \mathrm{~cm}$ compr. 11. Vochysia tucanorum

1. Callisthene major Mart., Nov. Gen. Sp. Pl. 1: 124; t. 75.1826. Fig. 1a-e

Arbusto ou árvore, $1,2-12 \mathrm{~m}$ alt.; ramos delgados, casca íntegra, râmulos jovens pubescentes, adultos glabros; estípulas inconspícuas. Folhas opostas, dísticas, dispostas em râmulos semelhantes a uma folha pinada; pecíolo 1-2 $\mathrm{mm}$ compr., pubescente; 5-10 pares de folhas por râmulo; lâmina $1,5-4 \times 1-1,5 \mathrm{~cm}$, as menores na base do râmulo, oval, oboval ou lanceolada, base arredondada a subcordada, ápice agudo ou arredondado, mucronado, face adaxial esparsamente pubescente, principalmente na nervura primária e nas margens, face abaxial pubescente ou esparsamente pubescente. Flores isoladas, axilares; botões florais 6-9 × ca. $3 \mathrm{~mm}$, retos, ápice agudo; cálcar $1,5-2 \times$ ca. $0,5 \mathrm{~mm}$, reto, perpendicular ao pedicelo, cilíndrico, aparente no botão floral; cálice pubescente, sépala calcarada ca. $10 \mathrm{~mm}$ compr.; pétala persistente durante a antese, ca. 1,5 $\times 1$ $\mathrm{cm}$, obcordada, branca, amarela ou creme, glabra; estame persistente durante a antese, filete ca. $6 \mathrm{~mm}$ compr., antera ca. $4 \mathrm{~mm}$ compr., glabra; ovário glabro. Cápsula ca. 1,5 cm compr., subglobosa a globosa, columela central engrossada, superfície lisa, exocarpo quebradiço facilmente separável do endocarpo. Sementes 1-2 por lóculo, circularmente aladas, ca. $1 \times 0,5 \mathrm{~cm}$.

Material selecionado: Capitólio, 28.IX.2005, fl. e fr., $R$. Romero et al. 7162 (HUFU). Delfinópolis, 15.IX.2004, fl., E.K.O. Hattori et al. 443 (HUFU).

Ocorre no Brasil nos estados da BA, GO, MG, MS, MT, PR, TO e no DF. No PNSC ocorre em locais próximos a cursos d'água. Floresce em setembro e frutifica em fevereiro, março, agosto e de setembro a novembro. Espécie reconhecida no PNSC por apresentar râmulos que se assemelham a uma folha pinada e flores pequenas nas axilas das folhas, com pétala branca, amarela ou creme.

2. Qualea cordata Spreng., Syst. Veg. (ed. 16) 1: 17. 1824.

Fig. 1f-j

Arbusto ou árvore, 1,5-4 m alt.; ramos cilíndricos com casca íntegra; estípulas glandulares crateriformes. Folhas opostas cruzadas; pecíolo 4-10 mm compr., glabro; lâmina 3-10,5 × 1-6 cm, elíptica a oval, ápice agudo a arredondado, base subcordada a cordada, face adaxial glabra, face abaxial glabra a pubescente. Tirsos terminais, 9-18 cm compr., cincinos 1-4-floros dispostos em pares opostos; pedicelos 2-4 mm compr.; botões florais 6-10× ca. $4 \mathrm{~mm}$, retos, ápice agudo; cálice desprovido de cálcar mas com protuberância bursiforme na base da quarta sépala, esta com 11-13 mm compr.; pétala persistente durante a antese, 1,5-2 × 1,5 cm, obcordada a orbicular, alva com manchas róseas, ou lilases, densamente serícea na face adaxial, pubescente na face abaxial; estame persistente durante a antese, filete 8-9 mm compr., antera ca. $5 \mathrm{~mm}$ compr., glabra; ovário 4-5 × ca. $3 \mathrm{~mm}$, seríceo. Cápsulas com até $2,5 \mathrm{~cm}$ compr., elipsóide, superfície verruculosa a lisa, não descamante; no fruto aberto, valvas não fundidas à região central, margens não reflexas. Sementes ca. 4 por lóculo, assimétricas, $1-1,8 \times$ ca. $0,2 \mathrm{~cm}$. Material selecionado: Capitólio, 16.II.2006, fr., $R$. Romero et al. 7622 (HUFU). Delfinópolis, 7.X.2002, fl. e fr., R. Romero et al. 6371 (HUFU).

Ocorre na Argentina, norte do Paraguai e no Brasil nos estados da BA, ES, GO, MG, MS, MT, PR, SC, SP e no DF. No PNSC é encontrada em campo rupestre, campo cerrado e campo sujo. Floresce em agosto, de outubro a dezembro e frutifica em janeiro, fevereiro, abril, maio, agosto e de outubro a dezembro. Reconhecida pela pétala alva com manchas lilases, com indumento em ambas as faces e sépala desprovida de cálcar, representado apenas por uma protuberância bursiforme.

3. Qualea grandiflora Mart., Nov. Gen. Sp. Pl. 1: 133. t. 79. 1826.

Fig. 1k-p

Arbusto ou árvore, 1,8-6 m alt.; ramos cilíndricos, casca descamante em placas; estípulas glandulares crateriformes ou planas. Folhas opostas cruzadas; pecíolo 7-16 mm compr., pubescente; lâmina $12,5-18 \times 5,5-7 \mathrm{~cm}$, oblonga a elíptica, cartácea a coriácea, ápice agudo a acuminado, base subcordada a cordada, face adaxial glabra, face abaxial tomentosa, nervuras enegrecidas (em material herborizado), proeminentes, convergindo em nervura coletora. Tirsos terminais, 7-12 cm compr., cincinos 1-4-floros dispostos em pares 

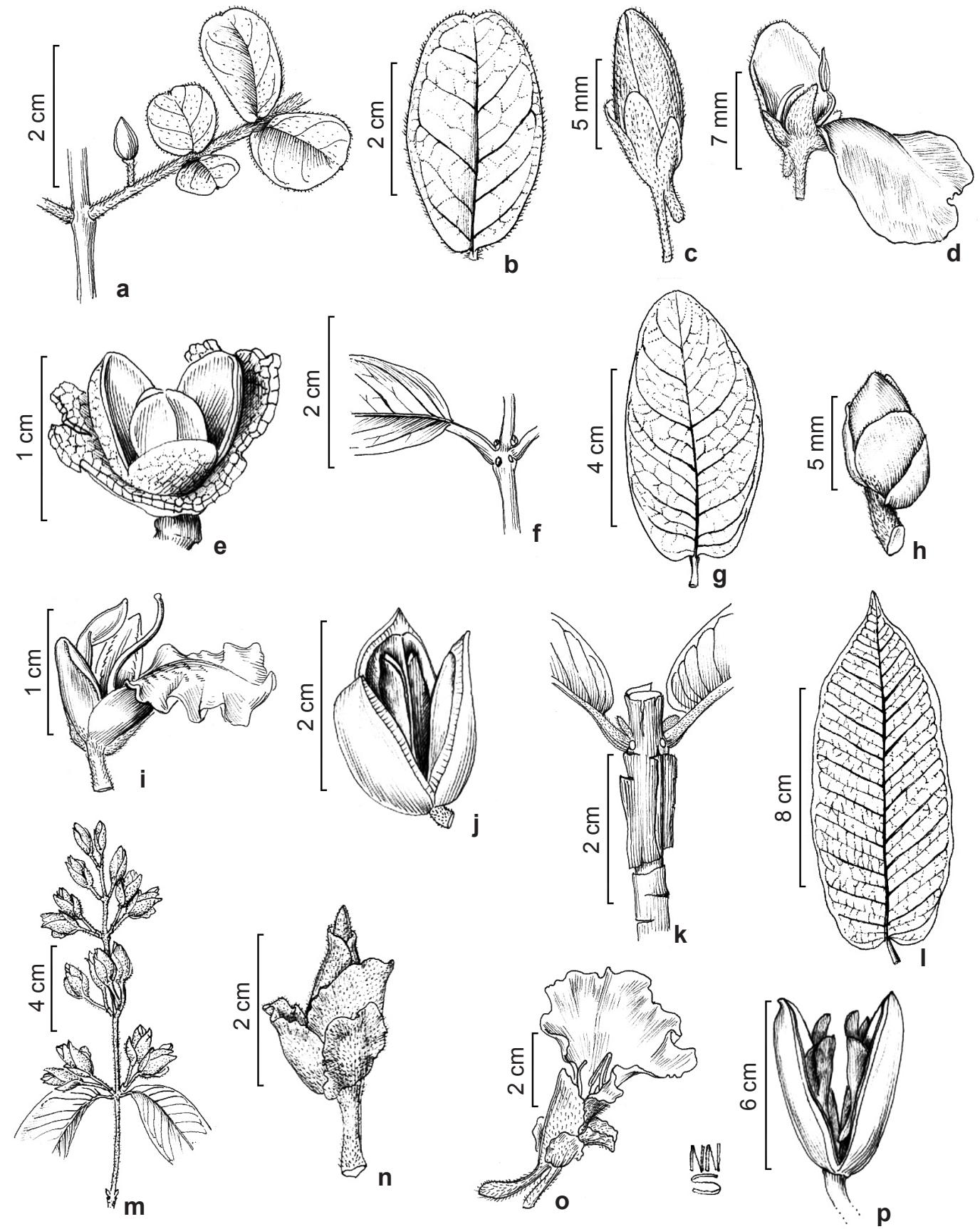

Figura 1 - a-e. Callisthene major - a. região nodal; b. folha; c. botão; d. flor; e. fruto (a-e Romero et al. 7162). f-j. Qualea cordata. - f. região nodal; g. folha; h. botão; i. flor; j. fruto (f, h, j Romero et al. 7622, g, i Romero et al. 8203). k-p. Q. grandiflora - k. região nodal; 1. folha; m. inflorescência; n. botão; o. flor; p. fruto (k Romero et al. 7353, 1-p Romero et al. 4876).

Figure 1 - a-e. Callisthene major - a. nodal region; b. leaf; c. bud; d. flower; e. fruit (a-e Romero et al. 7162). f-j. Qualea cordata - f. nodal region; g. leaf; h. bud; i. flower; j. fruit (f, h. j Romero et al. 7622, g, i Romero et al. 8203). k-p. Q. grandiflora - k. nodal region; 1. leaf; m. inflorescence; n. bud; o. flower; p. fruit (k Romero et al. 7353, 1-p Romero et al. 4876). 
opostos; pedicelos 1-1,5 mm compr.; botões florais 17-25 × 9-13 mm, retos, ápice agudo; cálcar ca. $20 \times 4 \mathrm{~mm}$, incurvo, cilíndrico, não aparente no botão floral, onde permanece dobrado entre as outras sépalas; sépala calcarada $18-22 \mathrm{~mm}$ compr.; pétala persistente durante a antese, $3,5-4 \times 4-4,5$ $\mathrm{cm}$, obcordada a orbicular com margens franzidas, amarela, glabra; estame persistente durante a antese, filete $7-12 \mathrm{~mm}$ compr., antera ca. $8 \mathrm{~mm}$ compr., glabra; ovário $4-5 \times$ ca. $4 \mathrm{~mm}$, seríceo. Cápsula 5,5-8 cm compr., ovóide, superfície levemente verruculosa, não descamante; no fruto aberto, valvas não fundidas à região central, margens não reflexas. Sementes 8 por lóculo, assimétricas, ca. $2,5 \times 0,7 \mathrm{~cm}$ compr.

Material selecionado: Capitólio, 7.XII.2005, fl., $R$. Romero et al. 7353 (HUFU). Delfinópolis, 20.XI.1999, fl., A.C.B. Silva 120 (SPFR).

Material adicional examinado: BRASIL. PIAUÍ: Piracuruca, 10.X.1998, fr., M.E. Alencar 422 (UEC). Brasileira, 22.VI.1999, fr., M.E. Alencar 719 (UEC). SÃO PAULO: Lençóis Paulista, 12.VI.1995, fr., J.Y. Tamashiro et al. 1077 (UEC).

Ocorre na Bolívia, Paraguai, Peru, Suriname e no Brasil nos estados do AC, AM, BA, CE, GO, MA, MG, MS, MT, PA, PI, PR, RO, SP, TO e no DF. No PNSC é encontrada em campo limpo associado a solo pedregoso, cerrado e cerrado rupestre. Floresce de novembro a janeiro. Difere das demais espécies por apresentar face abaxial com nervuras proeminentes e enegrecidas em material herborizado; no campo pode ser reconhecida por suas inflorescências vistosas com 7-12 cm de comprimento e flores e frutos de tamanho maior. Ademais, diferencia-se de Qualea multiflora e de Q. parviflora Mart. por apresentar casca dos ramos descamante em placas.

4. Qualea multiflora Mart., Nov. Gen. Sp. Pl. 1: 134. t. 80.1826.

Fig. $2 \mathrm{a}-\mathrm{f}$

Arbusto ou árvore, $0,4-6 \mathrm{~m}$ alt.; ramos cilíndricos, casca íntegra; estípulas glandulares crateriformes. Folhas opostas cruzadas ou em verticilos 3-meros; pecíolo 2-5 mm compr., glabro ou pubescente; lâmina $6,5-12,5 \times 2,5-4,2 \mathrm{~cm}$, oblonga, elíptica, oval a oboval, cartácea, ápice agudo a acuminado, base cuneada, arredondada a subcordada, face adaxial glabra, raramente glabrescente ou pubescente, face abaxial glabra ou pubescente. Tirsos terminais, 9,5-19 cm compr., cincinos 2-4-floros dispostos em pares opostos; pedicelos 4-12 mm compr.; botões florais 7-10 $\times 3-8 \mathrm{~mm}$, retos, ápice agudo; cálcar 3-7 × ca.
$2 \mathrm{~mm}$, recurvo, subclavado ou clavado, aparente no botão floral; sépala calcarada $8-9 \mathrm{~mm}$ compr.; pétala persistente durante a antese, ca. $2 \times 2,5 \mathrm{~cm}$, obcordada, alva ou amarela com manchas róseas a vináceas, glabra; estame persistente durante a antese, filete $7-9 \mathrm{~mm}$ compr., antera ca. $4 \mathrm{~mm}$ compr., glabra; ovário ca. $4 \times 3 \mathrm{~mm}$, seríceo. Cápsula ca. $3 \mathrm{~cm}$ compr., elipsóide, superfície verruculosa, não descamante; no fruto aberto, valvas não fundidas à região central, margens não reflexas. Sementes 2 por lóculo, assimétricas, ca. 1,5 ×0,5 cm.

Material selecionado: Capitólio, 9.XI.2007, fl., $R$. Romero et al. 8046 (HUFU). Delfinópolis, 10.IV.2002, fr., R. Romero et al. 6326 (HUFU).

Ocorre no norte do Paraguai, leste da Bolívia, Peru e no Brasil nos estado da BA, ES, GO, MA, MG, MS, MT, PA, PI, PR, RJ, RO, RR, SP, TO e no DF. No PNSC é encontrada em campo rupestre, cerrado rupestre, floresta de galeria e borda de capões. Floresce de novembro a janeiro e frutifica em abril. Stafleu (1953) descreveu $Q$. multiflora subsp. pubescens (Mart.) Stafleu devido à presença de indumento pubescente nas folhas, pecíolos e ramos, enquanto a subespécie típica não apresenta indumento. Decidimos não considerar estas subdivisões infra-específicas pois observamos um gradiente na densidade de indumento, desde ausente até densamente piloso, que impossibilita a delimitação das entidades. Qualea multiflora é reconhecida pelas folhas glabras a pubescentes, flores com indumento, exceto na antera e pétala e pela pétala alva ou amarela com manchas róseas a vináceas. Qualea multiflora é bastante semelhante à Q. grandiflora, porém seus frutos medem até $3 \mathrm{~cm}$ de comprimento, enquanto frutos de Q. grandiflora medem de 5,5 a $8 \mathrm{~cm}$ de comprimento. Além disso, as pétalas de $Q$. multiflora são menores, medindo $1,5-2 \times 4-4,5 \mathrm{~cm}$ e a casca dos ramos é íntegra, enquanto as pétalas de $Q$. grandiflora medem 3,5-4 $\times 4-4,5 \mathrm{~cm}$ e a casca dos ramos é descamante.

5. Qualea parviflora Mart., Nov. Gen. Sp. Pl. 1: 135. t.81. 1826.

Fig. 2g-1

Arbusto ou árvore, 2-7 m alt.; ramos cilíndricos, casca íntegra; estípulas glandulares crateriformes. Folhas opostas cruzadas ou em verticilos 3-meros; pecíolo 2-3 mm compr., glabro; lâmina 5,5-7 × 2-4,5 cm, elíptica ou oval, cartácea, glabra, ápice obtuso, arredondado, retuso ou emarginado, mucronado, base arredondada a cuneada. Tirsos terminais e subterminais, 13-17 cm compr., cincinos 2-6-floros dispostos em pares 

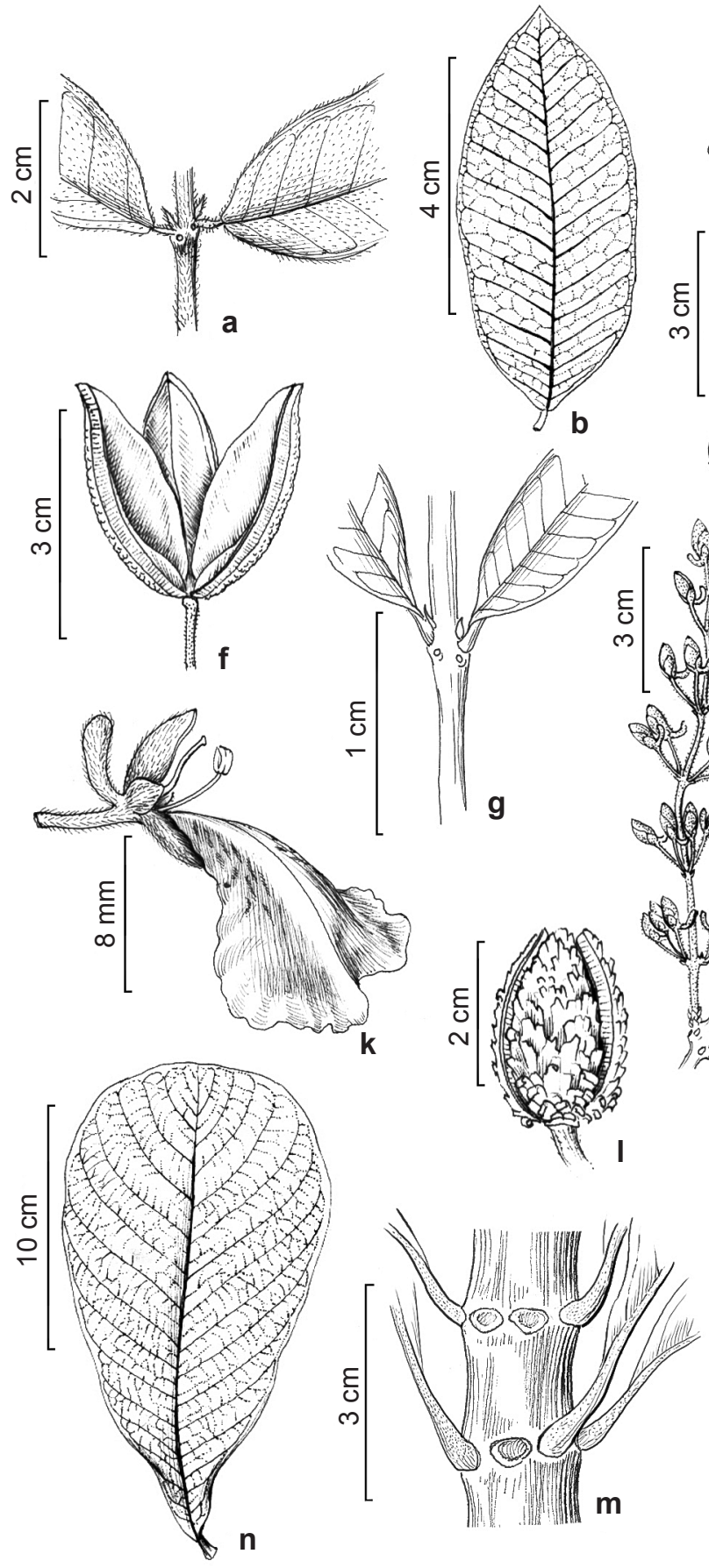
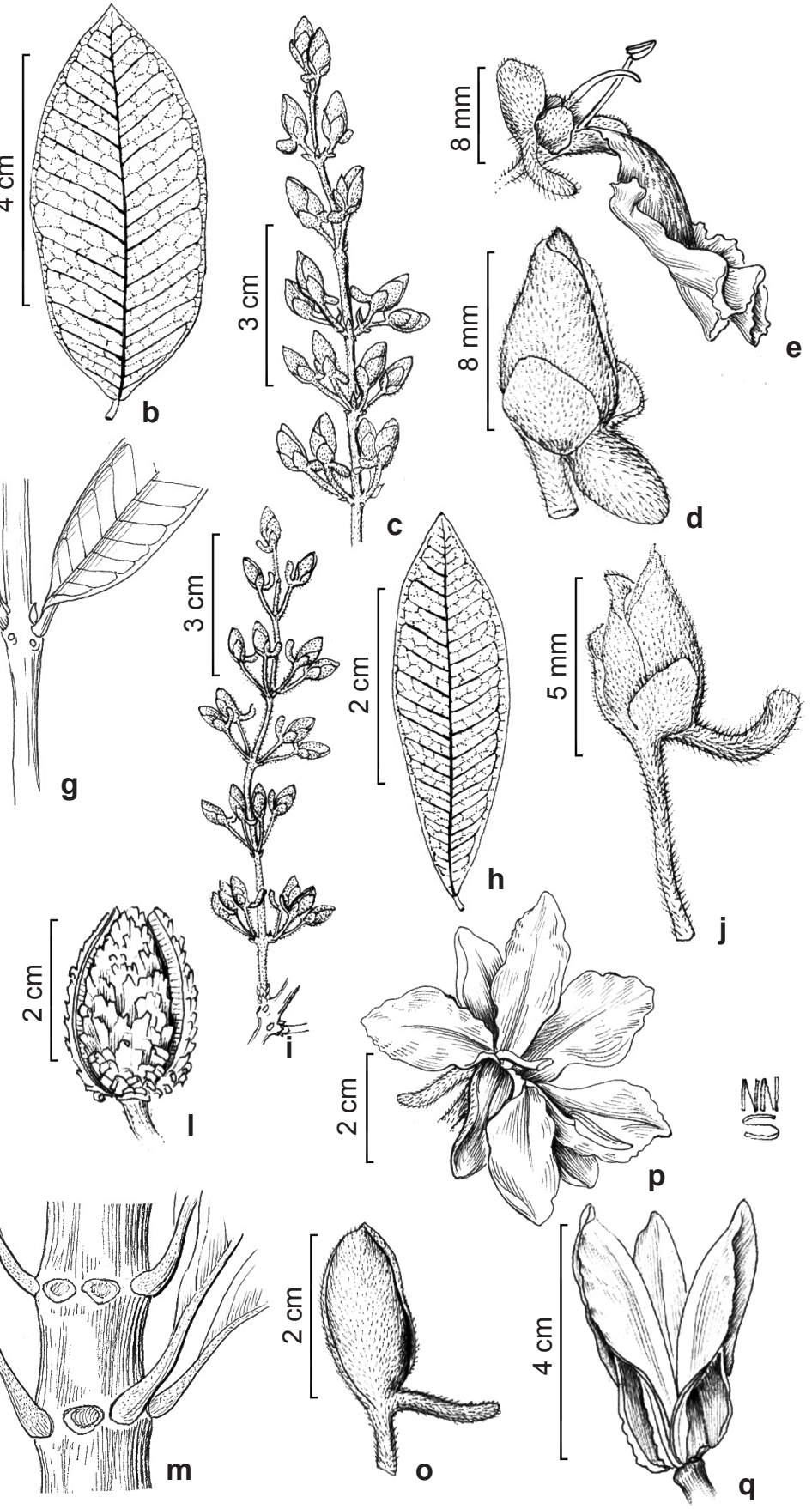

Figura 2 - a-f. Qualea multiflora - a. região nodal; b. folha; c. inflorescência; d. botão; e. flor; f. fruto (a-e Romero et al. 8046, f Romero et al. 6320). g-1. Q. parviflora - g. região nodal; h. folha; i. inflorescência; j. botão; k. flor; 1. fruto (g-h, j-1 Romero et al. 4689, i Volpi et al. 161). m-q. Salvertia convallariodora - m. região nodal; $\mathrm{n}$. folha; o. botão; p. flor; q. fruto (m-n Silva 458, o-q Nakajima et al. 3145).

Figure 2 - a-f. Qualea multiflora - a. nodal region; b. leaf; c. inflorescence; d. bud; e. flower; f. fruit (a-e Romero et al. 8046, f Romero et al. 6320). g-1. Q. parviflora - g. nodal region; h. leaf; i. inflorescence; j. bud; k. flower; 1. fruit (g-h, j-1 Romero et al. 4689, i Volpi et al. 161). m-q. Salvertia convallariodora A.St.-Hil. - m. nodal region; $n$. leaf; o. bud; p. flower; q. fruit (m-n Silva 458, o-q Nakajima et al. 3145). 
opostos; pedicelos 5-10 mm compr.; botões florais 5-6 × 3-4 mm, retos, ápice agudo; cálcar 2-6 $\times 1-2 \mathrm{~mm}$, reto, recurvo, subclavado a clavado, raro cilíndrico, aparente no botão floral; sépala calcarada 6-8 $\mathrm{mm}$ compr.; pétala persistente durante a antese, ca. 1,2 × 1,2-1,4 cm, obcordada, violácea a vinácea com manchas lilases, glabra, esparsamente pilosa apenas na porção basal da face abaxial; estame persistente durante a antese, filete ca. $4 \mathrm{~mm}$ compr., antera ca. 1,5 mm compr., glabra; ovário ca. $3 \times 2 \mathrm{~mm}$, seríceo. Cápsula 2,5-3,5 cm compr., elipsóide, superfície lisa, levemente descamante; no fruto aberto, valvas não fundidas à região central, margens não reflexas. Sementes 2 por lóculo, assimétricas, ca. $2,2 \times 0,5 \mathrm{~cm}$.

Material selecionado: Capitólio, 23.V.2007, fr., P.H.N. Bernardes et al. 237 (HUFU). Delfinópolis, 19.XI.1999, fl., A.C.B. Silva 69 (SPFR).

Ocorre no leste da Bolívia, norte do Paraguai e no Brasil nos estados do AM, BA, CE, GO, MA, MG, MS, MT, PA, PI, SP, TO e no DF. No PNSC é encontrada em cerrado, cerrado rupestre e campo rupestre. Floresce em abril e de outubro a dezembro e frutifica em maio e dezembro. Qualea parviflora pode ser diferenciada de $Q$. multiflora e de $Q$. grandiflora por apresentar corola violácea a vinácea com guias e manchas lilases, além dos frutos bem característicos com superfície levemente descamante.

\section{Salvertia convallariodora A.St.-Hil., Mém.} Mus. Hist. Nat. 6: 259. $1820 . \quad$ Fig. 2m-q

Arbusto ou árvore, 2,5-5 m alt.; ramos cilíndricos, casca íntegra; estípulas glandulares ausentes. Folhas em verticilos 6-7-meros; pecíolo 10-25 mm compr., esparsamente pubescente; lâmina 14-23 × 6-14 cm, oboval, glabra a glabrescente, base cuneada, ápice arredondado ou emarginado. Tirsos terminais, 30-67 × 11-14 $\mathrm{cm}$, cincinos 2-4-floros dispostos em verticilos, indumento ferrugíneo pubescente; pedicelos 5-10 $\mathrm{mm}$ compr.; botões florais $20-25 \times 5-10 \mathrm{~mm}$, retos, ápice arredondado; cálcar 10-15 × 20-30 $\mathrm{mm}$, reto ou incurvo, cilíndrico, aparente no botão floral. Cálice e corola pentâmeros, sépala calcarada ca. $30 \mathrm{~mm}$ compr.; 5 pétalas persistentes durante a antese, ca. $3 \times 1,5 \mathrm{~cm}$, obovais a oblongas, alvas, glabras; estame persistente durante a antese, filete 10-14 mm compr., antera ca. $17 \mathrm{~mm}$ compr., glabra; ovário 4-5 × 3-4 mm, seríceo. Cápsula ca. 4,4 cm compr., oblonga, superfície lisa, não descamante; no fruto aberto, valvas parcialmente fundidas à região central, margens reflexas. Semente 1 por lóculo, assimétrica, ca. $4 \times 1,2 \mathrm{~cm}$ (Stafleu 1948).

Material selecionado: Delfinópolis, 3.V.2001, fl., A.C.B. Silva 960 (SPFR).

Material adicional examinado: BRASIL. SÃO PAULO: Pedregulho, 26.VII.1991, fl. e fr., W. Marcondes-Ferreira et al. 367 (UEC).

Ocorre na Bolívia, Suriname e no Brasil nos estados AM, AP, BA, GO, MA, MG, MS, MT, PA, PI, SP, TO e no DF. No PNSC é encontrada em campo rupestre e cerrado. Floresce em abril e maio. Facilmente reconhecida por apresentar flores vistosas, pentâmeras, com pétalas alvas, inflorescências com 30-67 cm de comprimento e folhas com 14-23 × 6-14 cm.

7. Vochysia cinnamomea Pohl, Pl. Bras. Icon. Descr. 2: 29. t. 120. 1831.

Fig. 3a-f

Arbusto ou árvore, $0,7-5 \mathrm{~m}$ alt.; ramos cilíndricos, casca descamante em placas, indumento ferrugíneo; estípulas glandulares ausentes. Folhas em verticilos 3-6-meros, congestas no ápice dos ramos; pecíolo 3-6 mm compr., densamente canescente; lâmina 7-19 × 2,5-6,5 cm, elíptica ou oblongo-elíptica, base cuneada, ápice retuso, mucronado ou arredondado, indumento glabrescente na face adaxial, face abaxial de folhas jovens com indumento cinamômeo e de folhas velhas com indumento canescente. Tirsos terminais, $29-32 \mathrm{~cm}$ compr., cinamômeo-tomentoso, principalmente nas porções jovens, cincinos 2-floros dispostos de forma alterna espiralada; pedicelos 3-8 $\mathrm{mm}$ compr.; botões florais 9-14 × 2-3 mm, incurvos, cilíndricos, ápice arredondado; cálcar 7-11 × ca. $2 \mathrm{~mm}$, reto a incurvo, cilíndrico, ápice arredondado, aparente no botão floral; sépala calcarada 16-24 $\mathrm{mm}$ compr., 3 pétalas decíduas, amarelas, glabras; estame decíduo durante a antese; filete ca. $4 \mathrm{~mm}$ compr., antera ca. $12 \mathrm{~mm}$ compr., glabra; ovário $3,5 \times 2,5 \mathrm{~mm}$, adpresso-seríceo. Cápsula 2,5-3 cm compr., oblonga, superfície levemente verruculosa; no fruto aberto, valvas parcialmente fundidas à região central, margens reflexas. Semente 1 por lóculo, assimétrica, ca. $3 \times 0,5 \mathrm{~cm}$.

Material selecionado: Capitólio, 7.XII.2005, fl., $R$. Romero et al. 7361 (HUFU). São Roque de Minas, 9.X.2002, fr., J.N. Nakajima et al. 3220 (HUFU).

Ocorre no norte do Paraguai e no Brasil nos estados de GO, MG, MS, MT, RO e SP. No PNSC é encontrada em campo rupestre e cerrado rupestre. Floresce de fevereiro a maio, julho e dezembro e frutifica em maio e outubro. Vochysia cinnamomea 

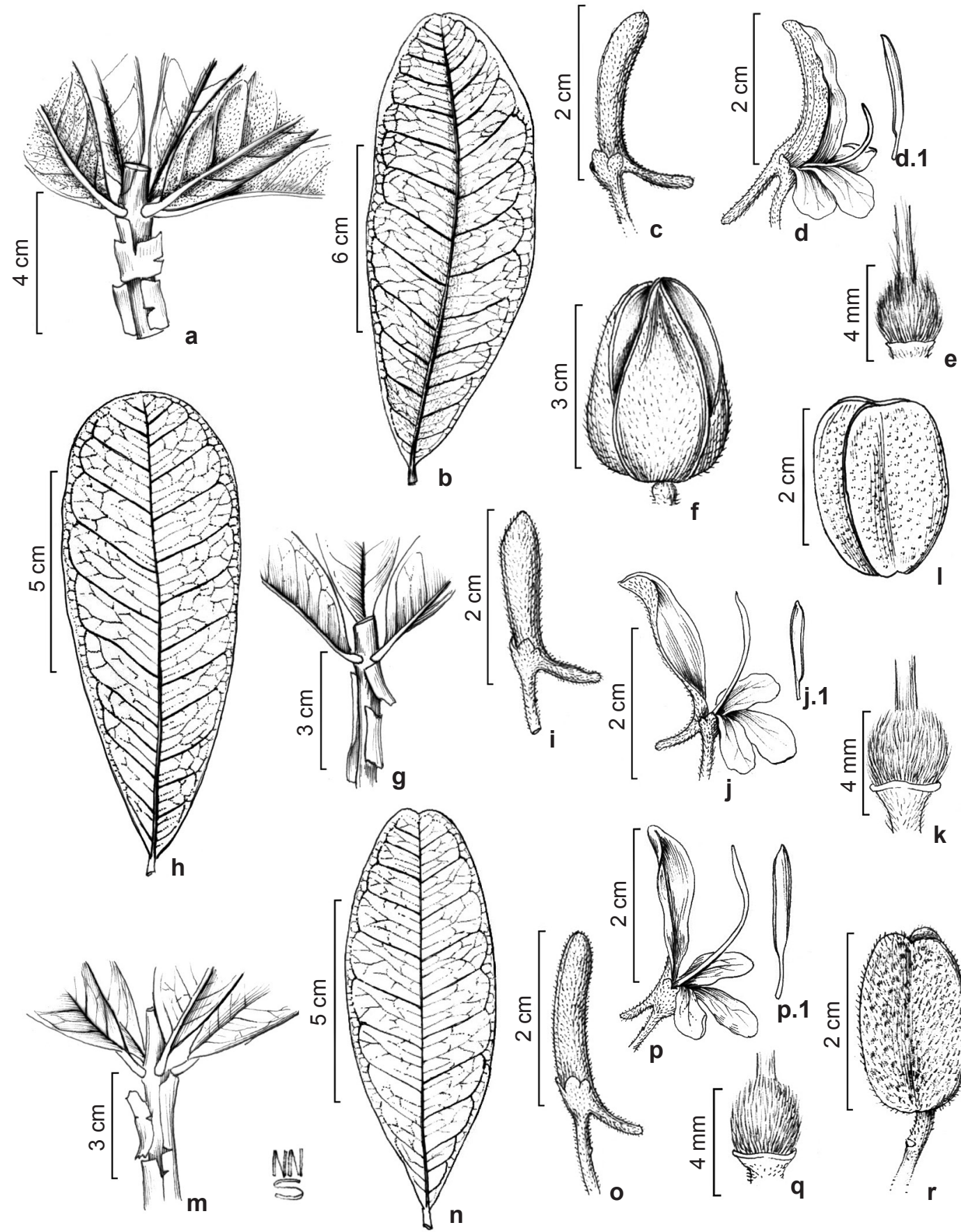

Figura 3 - a-f. Vochysia cinnamomea - a. região nodal; b. folha; c. botão; d. flor, d.1. estame; e. ovário; f. fruto (a, c-e Nakajima et al. 3147, b, f Nakajima et al. 3220). g-1. V. elliptica-g. região nodal; h. folha; i. botão; j. flor, j.1. estame; k. ovário; 1. fruto (g-1 Pacheco et al. 111). m-r. V. sessilifolia - m. região nodal; n. folha; o. botão; p. flor, p.1. estame; q. ovário; r. fruto (m-r Nakajima et al. 3495).

Figure 3 - a-f. Vochysia cinnamomea - a. nodal region; b. leaf; c. bud; d. flower, d.1. stamen; e. ovary; f. fruit (a, c-e Nakajima et al. 3147, b, f Nakajima et al. 3220). g-1. V. elliptica - g. nodal region; h. leaf; i. bud; j. flower, j.1. stamen; k. ovary; 1. fruit (g-1 Pacheco et al. 111). m-r. V. sessilifolia - m. nodal region; n. leaf; o. bud; p. flower, p.1. stamen; q. ovary; r. fruit (m-r Nakajima et al. 3495). 
se assemelha a $V$. rufa Mart., da qual se diferencia por apresentar indumento amarronzado em folhas jovens e acinzentado em folha mais velhas, face abaxial da lâmina foliar com indumento mais denso, e ramos mais abertos, não formando copa. Além destas características, também pode ser facilmente reconhecida por suas folhas congestas no ápice dos ramos. Sasaki \& Mello-Silva (2008) relacionam a ocorrência das duas espécies para Pedregulho, São Paulo, região próxima ao Parque. No presente estudo, após uma análise minuciosa de todas as coleções da Serra da Canastra, constatamos a ocorrência de apenas $V$. cinnamomea.

Vochysia cinnamomea se assemelha também a $V$. sessilifolia Mart. e a $V$. elliptica Mart., ambas com ocorrência na Serra da Canastra. Contudo, diferencia-se de $V$. sessilifolia, principalmente, pelas folhas congestas no ápice dos ramos florígenos, e de $V$. elliptica por esta apresentar folhas glabras e ápice do botão floral apiculado, enquanto $V$. cinnamomea apresenta folhas adultas com indumento glabrescente, folhas jovens densamente pilosas e ápice do botão floral arredondado.

8. Vochysia elliptica Mart., Nov. Gen. Sp. P1. 1: 141. t. 84. 1826.

Fig. 3g-1

Arbusto, 0,5-1,5 m alt.; ramos cilíndricos, casca descamante em placas, glabra, raramente pubescente; estípulas glandulares ausentes. Folhas em verticilos 3-4-meros, dispostas ao longo dos ramos; pecíolo 2-6 mm compr., glabro a glabrescente; lâmina 5-10 × 3-4 cm, elíptica, oboval ou oblonga, glauca, glabra, ápice arredondado, obtuso, retuso ou emarginado, às vezes com múcron, base aguda, obtusa ou arredondada. Tirsos terminais ou terminais e axilares, 19-43 cm compr., cincinos 2-3-floros dispostos de forma alterna espiralada, indumento ferrugíneo-tomentoso; pedicelos 5-10 mm compr.; botões florais 10-17 mm compr., retos a incurvos, cilíndricos, ápice agudo ou apiculado; cálcar 5-9 × 1-1,5 mm, incurvo, cilíndrico, ápice arredondado, aparente no botão floral; sépala calcarada ca. $22 \mathrm{~mm}$ compr.; 3 pétalas decíduas, amarelas, glabras; estame decíduo durante a antese, filete ca. $5 \mathrm{~mm}$ compr., antera 12-15 mm compr., glabra; ovário ca. $3 \times 3$ $\mathrm{mm}$, seríceo. Cápsula 2-2,5 cm compr., elipsóide a oblonga, superfície verruculosa, indumento ferrugíneo; no fruto aberto, valvas parcialmente fundidas à região central, margens reflexas. Semente 1 por lóculo, assimétrica, ca. $2,2 \times 1 \mathrm{~cm}$.

Material selecionado: Delfinópolis, 27.II.2000, fl., A.C.B. Silva \& S.A.P. Godoy 628 (SPFR); 14.IX.2004, fl. e fr., C.A. Faria et al. 39 (HUFU).
Ocorre nos estados da BA, GO, MG, MT, RJ, TO e no DF. No PNSC é encontrada em campo rupestre e campo limpo associado a afloramentos rochosos. Floresce de fevereiro a maio, setembro e outubro e frutifica em maio, setembro e outubro. Reconhecida pela associação dos seguintes caracteres: folhas glaucas, elípticas, obovais ou oblongas, botões florais com ápice agudo ou acuminado, indumento ferrugíneo nos eixos das inflorescências, nos pedúnculos, pedicelos, partes externas das flores e nos frutos.

9. Vochysia sessilifolia Warm., in Mart. \& Eichler, Fl. bras. 13(2): 67.1875.

Fig. $3 \mathrm{~m}-\mathrm{r}$

Subarbusto, ca. 1,5 m alt.; ramos cilíndricos, casca descamante em placas, glabra; estípulas glandulares ausentes. Folhas em verticilos 4-meros, dispostas de forma laxa ao longo dos ramos; pecíolo 3-5 mm compr., glabro; lâmina 9,5-15,5 $\times 3,5-4,5 \mathrm{~cm}$, oboval, glabra, ápice retuso, às vezes com múcron, base cuneada. Tirsos terminais, 43-50,5 cm compr., cincinos 2-4-floros dispostos de forma alterna espiralada; pedicelos 9-15 mm compr.; botões florais $10-15 \times 3-5 \mathrm{~mm}$, retos a incurvos, cilíndricos, ápice arredondado; cálcar 4-7 $\times$ 1-2 mm, incurvo, cilíndrico, ápice arredondado, aparente no botão floral; sépala calcarada ca. 22 mm compr.; 3 pétalas decíduas, amarelas, glabras; estame decíduo durante a antese, filete ca. $5 \mathrm{~mm}$ compr., antera 12-14 mm compr., glabra; ovário ca. $3 \times 2,5 \mathrm{~mm}$, seríceo. Cápsula ca. 2,5 cm compr., oblonga, superfície lisa, indumento cinamômeo canescente; no fruto aberto, valvas parcialmente fundidas à região central, margens reflexas. Semente 2-2,5 × $1 \mathrm{~cm}$ (Barbosa 1999).

Material selecionado: Delfinópolis, 13.III.2003, fl., J.N. Nakajima 3495 (HUFU); 14.IX.2000, fl. e fr., A.C.B. Silva 585 (HUFU).

Material adicional examinado: BRASIL. SÃO PAULO: Pedregulho, Estreito, 12.VII.1995, fr., $W$. Marcondes-Ferreira 1237 (UEC).

Ocorre no Brasil nos estados de MG, MT e SP. No Parque é encontrada exclusivamente em campo rupestre. Floresce em novembro e março. Reconhecida pelas folhas laxas ao longo dos ramos e inflorescências mais longas (43-50,5 cm compr.) dentre as espécies de Vochysia que ocorrem no PNSC.

10. Vochysia thyrsoidea Pohl, Pl. Bras. Icon. Descr. 2: 24. t. 115. 1831.

Fig. 4a-f

Arbusto ou árvore, 3-7,5 m alt.; ramos subquadrangulados, casca íntegra; estípulas glandulares ausentes. Folhas em verticilos 


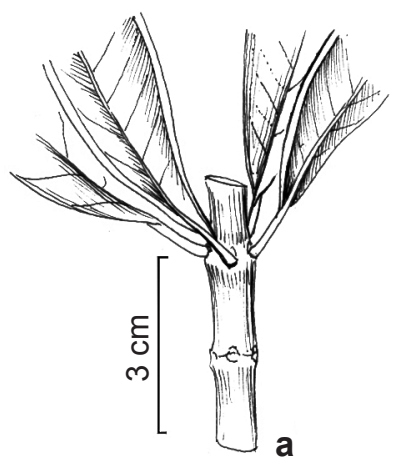

है
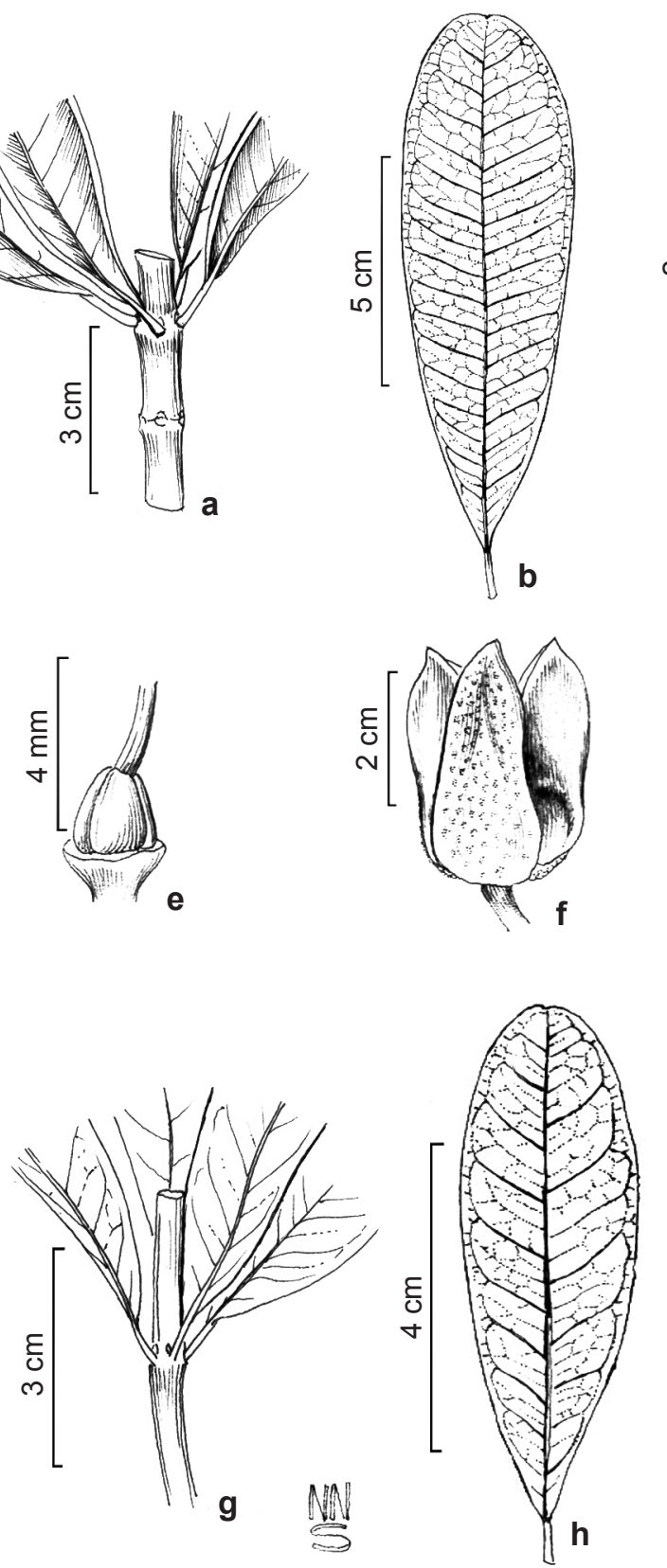
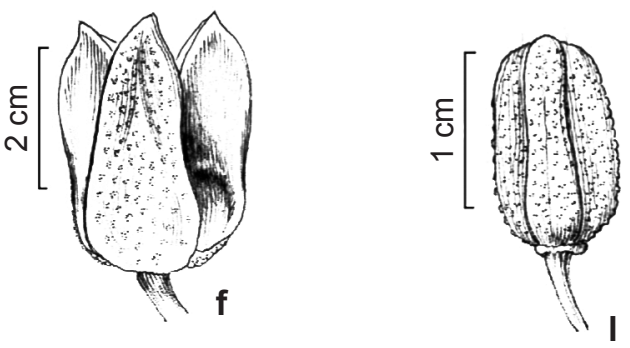
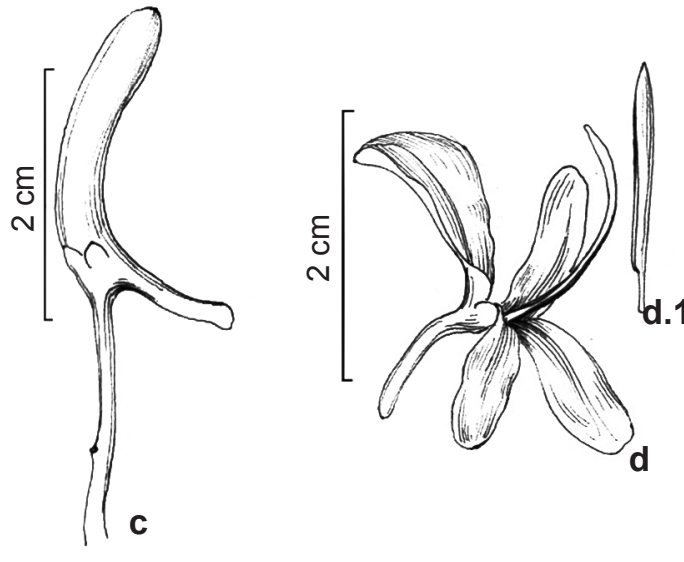

.1
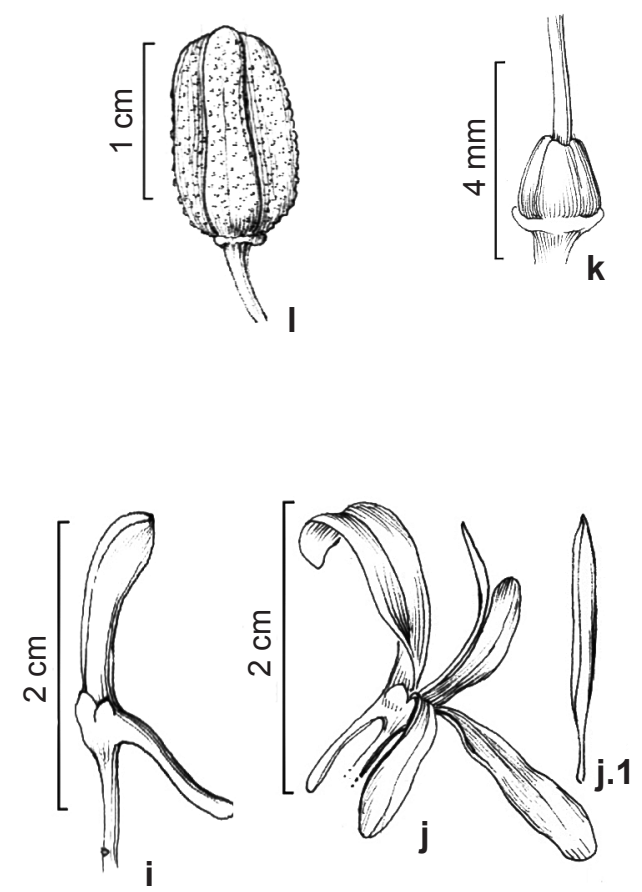

Figura 4 - a-f. Vochysia thyrsoidea - a. região nodal; b. folha; c. botão; d. flor, d.1. estame; e. ovário; f. fruto (a-c, f Volpi 788, d-e Romero et al. 3190). g-1. V. tucanorum - g. região nodal; h. folha; i. botão; j. flor, j.1. estame; k. ovário; 1. fruto (g Nakajima et al. 2037, h, 1 Rosa et al. 513, j-k Nakajima et al. 2037).

Figure 4 - a-f. Vochysia thyrsoidea - a. nodal region; b. leaf; c. bud; d. flower, d.1. stamen; e. ovary; f. fruit (a-c, f Volpi 788, d-e. Romero et al. 3190). g-1. V. tucanorum - g. nodal region; h. leaf; i. bud; j. flower, j.1. stamen; k. ovary; 1. fruit (g Nakajima et al. 2037, h, 1 Rosa et al. 513, j-k Nakajima et al. 2037).

4-5-meros; pecíolo 9-14 mm compr., glabrescente; lâmina $8-12,5 \times 2-4,5 \mathrm{~cm}$, oboval ou elíptica, coriácea, glabra, ápice retuso ou emarginado, às vezes com múcron, base cuneada ou atenuada, margem fortemente revoluta em toda a lâmina.
Tirsos terminais, 15-25 $\mathrm{cm}$ compr., cincinos 2-4-floros dispostos de forma alterna espiralada; pedicelos 6-13 mm compr.; botões florais 13-19× 2-4 mm, retos a levemente incurvos, cilíndricos a subclavados, ápice obtuso; cálcar 3,5-8 × 1,5-2,5 
$\mathrm{mm}$, reto a recurvo, cilíndrico, ápice arredondado, aparente no botão floral; sépala calcarada 20-25 × 6-10 mm; 3 pétalas decíduas, amarelas, glabras; estame decíduo durante a antese, filete ca. 7,5 mm compr., antera 15-23 mm compr., ciliada nas bordas das tecas; ovário ca. 1,5 × 2 mm, glabro. Cápsula 3-4 cm compr., oblonga ou oval, superfície verruculosa, glabra; no fruto aberto, valvas parcialmente fundidas à região central e margens reflexas. Semente 1 por lóculo, assimétrica, ca. 2,3 × 0,7 cm.

Material selecionado: Capitólio, 26.X.2006, fl., J.N. Nakajima et al. 4308 (HUFU). São Roque de Minas, 17.IV.1994, fr., J.N. Nakajima et al. 288 (HUFU).

Ocorre no Brasil nos estados da BA, CE, GO, MG, SP e no DF. No PNSC é encontrada em campo rupestre e campo limpo associado a afloramentos rochosos. Floresce de outubro a dezembro e frutifica em abril. Vochysia thyrsoidea é reconhecida pelas folhas coriáceas com margem fortemente revoluta. No campo é facilmente reconhecida pelos ramos abertos e voltados para cima. Dentre as espécies do gênero encontradas no PNSC, assemelha-se a $V$. tucanorum Mart. pelos ramos com casca não descamante em placas e ovário glabro. As duas espécies se diferenciam pelas dimensões das estruturas vegetativas e reprodutivas e pela textura das folhas (folhas fortemente coriáceas, com 8-12,5 cm compr. em $V$. thyrsoidea $\mathrm{x}$ folhas cartáceas com até 9,5 cm compr. em $V$. tucanorum). Além disso, Vochysia thyrsoidea apresenta ápice do botão floral obtuso e em $V$. tucanorum o ápice do botão floral é arredondado a agudo.

11. Vochysia tucanorum Mart., Nov. Gen. Sp. Pl. 1: 142 . t. 85. 1826.

Fig. 4g-1

Arbusto ou árvore, 0,5-10 m alt.; ramos subquadrangulados, casca íntegra; estípulas glandulares ausentes. Folhas em verticilos 3-4-meros; pecíolo 3-12 cm compr., glabro; lâmina 5,5-9,5 × 1,5-3,5 cm, oboval ou elíptica, cartácea, glabra, ápice retuso ou emarginado, base cuneada ou atenuada; margem plana, às vezes levemente revoluta apenas na porção basal. Tirsos terminais, $15,5-24,5 \mathrm{~cm}$ compr., cincinos 2-4-floros dispostos de forma alterna espiralada; pedicelos 4-10 mm compr.; botões florais 7-14 × 2-3 mm, incurvos, cilíndricos, ápice arredondado a agudo; cálcar 8-9 × 0,5-1 mm, reto ou recurvo, cilíndrico, ápice arredondado, aparente no botão floral; sépala calcarada ca. $22 \mathrm{~mm}$ compr., 3 pétalas decíduas, amarelas, glabras ou ciliadas na margem; estame decíduo durante a antese, filete ca. $3 \mathrm{~mm}$ compr., antera 15-23 mm compr., ciliada na borda das tecas; ovário ca. 2,5 × 1,5 mm, glabro. Cápsula ca. 1,8 cm compr., oblonga ou elíptica, superfície levemente verruculosa, glabra; no fruto aberto, valvas parcialmente fundidas à região central e margens reflexas. Semente 1 por lóculo, assimétrica, ca. $1,3 \times 0,4 \mathrm{~cm}$.

Material selecionado: Capitólio, 14.V.2003, fr., R.A. Pacheco et al. 552 (HUFU). São Roque de Minas, 10.IV.1994, fr., R. Romero et al. 971 (HUFU).

Ocorre na Bolívia, norte do Paraguai e no Brasil nos estados da BA, ES, GO, MG, MS, MT, PR, RJ, SP, TO e no DF. No PNSC é encontrada no interior e borda de florestas em vertentes de córregos, ocasionalmente ocorrendo em campo rupestre, campo sujo e cerrado. Floresce em janeiro e março e de novembro a dezembro e frutifica de março a maio. Vochysia tucanorum assemelha-se a $V$. thyrsoidea, da qual se diferencia pela dimensão menor das estruturas vegetativas e reprodutivas. As diferenças entre essas duas espécies são discutidas nos comentários de $V$. thyrsoidea.

\section{Agradecimentos}

Ao CNPq, a bolsa de iniciação científica concedida à primeira autora; aos curadores dos herbários SPFR e UEC, o envio dos materiais; ao Dr. Jimi Naoki Nakajima, ao Dr. Paulo Eugênio Alves Macedo de Oliveira, ao Msc. Gustavo Hiroaki Shimizu e à Msc. Priscila Oliveira Rosa, a leitura e sugestões; a Natanael Nascimento Santos, as ilustrações.

\section{Referências}

Barbosa, A.R. 1999. As espécies do gênero Vochysia Aubl. (Vochysiaceae) ocorrentes no estado de São Paulo. Dissertação de Mestrado. Universidade Estadual de Campinas, Campinas. 196p.

Carvalho-Silva, M. \& Guimarães, E.F. 2009. Piperaceae do Parque Nacional da Serra da Canastra, Minas Gerais, Brasil. Boletim de Botânica da Universidade de São Paulo 27: 235-245.

Dumortier, B.C. 1829. Vochysiaceae. In: Dumortier, B.C. Analyse des familles des plantes avec l'indication des principaux genres qui s'y rattachent. J. Casterman, Tournay. 41p.

Farinaccio, M.A. \& Mello-Silva, R. 2004. Asclepiadoideae (Apocynaceae) do Parque Nacional da Serra da Canastra, Minas Gerais, Brasil. Boletim de Botânica da Universidade de São Paulo 22: 53-92.

Filardi, F.L.R.; Garcia, F.C.P.; Dutra, V.F. \& São-Thiago, P.S. 2007. Papilionoideae (Leguminosae) do Parque Nacional da Serra da Canastra, Minas Gerais, Brasil. Hoehnea 34: 383-408. 
França, F. 2013. Vochysiaceae. In: Lista de espécies da flora do Brasil. Jardim Botânico do Rio de Janeiro. Disponível em $<$ http://floradobrasil.jbrj. gov.br/jabot/floradobrasil/FB250>. Acesso em 6 Jun 2013.

Hemsing, P.K.B. \& Romero, R. 2010. Chrysobalanaceae do Parque Nacional da Serra da Canastra, Minas Gerais, Brasil. Rodriguésia 61: 281-288.

Ibama - Instituto Brasileiro do Meio Ambiente. 2005. Plano de Manejo do Parque Nacional da Serra da Canastra. IBDF, Brasília. 799p.

Lista de Espécies da Flora do Brasil. Disponível em <http://reflora.jbrj.gov.br/jabot/listaBrasil/ ConsultaPublicaUC/ConsultaPublicaUC.do $>$. Acesso em 6 Jun 2013.

Litt, A. \& Stevenson, D.W. 2003. Floral development and morphology of Vochysiaceae. I. The structure of the gynoecium. American Journal of Botany 90: 1533-1547.

Mendonça, R.C.; Felfili, J.M.; Walter, B.M.T.; Júnior, M.C.S.; Rezende, A.V.; Filgueiras, T.S.; Nogueira, P.E. \& Fagg, C.W. 2008. Flora vascular do Bioma Cerrado: check list com 12.356 espécies. In: Sano, S.M.; Almeida, S.P. \& Ribeiro, J.F. (org.). Cerrado: ecologia e flora. Vol. 2. Embrapa Informação Tecnológica, Brasília, DF. Pp. 1170-1173.

Morokawa, R., Simões, A.O. \& Kinoshita, L.S. 2013. Apocynaceae s. str. do Parque Nacional da Serra da Canastra, Minas Gerais, Brasil. Rodriguésia 64: 179-199.

Nakajima, J.N. \& Semir, J. 2001. Asteraceae do Parque Nacional da Serra da Canastra, Minas Gerais, Brasil. Revista Brasileira de Botânica 24: 471-478.

Pontes, A.F. \& Mello-Silva, R. 2005. Annonaceae do Parque Nacional da Serra da Canastra, Minas Gerais, Brasil. Boletim de Botânica da Universidade de São Paulo 23: 71-84.

Radford, A.E.; Dickison, W.C.; Massey, J.R. \& Bell, C.R. 1974. Vascular plant systematics. Harper and Row, New York. Pp. 79-166.

Romero, R. \& Martins, A.B. 2002. Melastomataceae do Parque Nacional da Serra da Canastra, Minas Gerais, Brasil. Revista Brasileira de Botânica 25: 19-24.
Romero, R. \& Nakajima, J.N. 1999. Espécies endêmicas do Parque Nacional da Serra da Canastra, Minas Gerais. Revista Brasileira de Botânica 22: 259-265.

Sarmiento, G. 1983. The savannas of tropical America. In: Bouliere, F. (ed.). Ecosystems of the world: tropical savannas. Elsevier, Amsterdam. Pp. 245-288.

Sasaki, D. \& Mello-Silva, R. 2008. Levantamento florístico no cerrado de Pedregulho, SP, Brasil. Acta Botanica Brasilica 22: 187-202.

Scudeller, V.V. 2004. Bignoniaceae Juss. no Parque Nacional da Serra da Canastra - Minas Gerais, Brasil. Iheringia, série Botânica 59: 59-73.

Silva, M.A.O. \& Romero, R. 2008. Melastomataceae das serras do município de Delfinópolis, Minas Gerais, Brasil. Rodriguésia 59: 609-647.

Silveira, M.F. 2010. Rubiaceae-Rubioideae Verdc. do Parque Nacional da Serra da Canastra, Minas Gerais, Brasil. Dissertação de Mestrado. Universidade Estadual de Campinas, Campinas. 118p.

Stafleu, F.A. 1948. A monograph of Vochysiaceae. I. Salvertia and Vochysia. Recueil des Travaux Botaniques Néerlandais 41: 397-540.

Stafleu, F.A. 1952. A monograph of Vochysiaceae. II. Callisthene. Acta Botanica Neerlandica 1: 222-242.

Stafleu, F.A. 1953. A monograph of Vochysiaceae. III. Qualea. Acta Botanica Neerlandica 2: 144-217.

Stearn, W.T. 2004. Botanical Latin. $4^{\text {th }}$ ed. Timber Press, Portland. 546p.

Thiers, B. 2012. Index Herbariorum: A global directory of public herbaria and associated staff. New York Botanical Garden's Virtual Herbarium. Disponível em $<$ http://sweetgum.nybg.org/ih $>$. Acesso em 15 Mai 2012.

Tropicos.org. 2013. Missouri Botanical Garden. Disponível em $<$ http://www.tropicos.org $>$. Acesso em 16 Ago 2012.

Volpi, R.L. 2006. Malpighiaceae no Parque Nacional da Serra da Canastra, Minas Gerais, Brasil. Dissertação de Mestrado. Universidade Federal do Paraná, Curitiba. $118 \mathrm{p}$.

Yamamoto, K. 2009. Flora de Grão-Mogol, Minas Gerais: Vochysiaceae. Boletim de Botânica da Universidade de São Paulo 27: 131-136.

\section{Lista de exsicatas}

Alencar, M.E.: 422(3), 719(3). Bernardes, P.H.N.: 237(5). Faria, C.A.: 39(8). Hattori, E.K.O.: 443(1). Marcondes-Ferreira, W.: 1237 (9), 367(6). Nakajima, J.N.: 288(10), 2037(11), 3145(6), 3147(7), 3220(7), 3495(9), 3588(1), 4308(10). Pacheco, R.A.: 111(8), 629(8). Romero, R.: 971(11), 3190(10), 4689(5), 4876(3), 6320(4), 6326(4), 6341(5), 6371(2), 7162(1), 7353(3), 7361(7), 7622(2), 8046(4), 8203(2). Rosa, P.O.: 513(11). Silva, A.C.B.: 120(3), 268(8), 458(6), 585(9), 69(5), 960(6). Tamashiro, J.Y.: 1077(3). Volpi, R.L.: 161(5), 788(10). 